\title{
Atmospheric number size distributions of soot particles and estimation of emission factors
}

\author{
D. Rose $^{1}$, B. Wehner ${ }^{1}$, M. Ketzel ${ }^{2}$, C. Engler ${ }^{1}$, J. Voigtländer ${ }^{1}$, T. Tuch ${ }^{1,3}$, and A. Wiedensohler ${ }^{1}$ \\ ${ }^{1}$ Leibniz Institute for Tropospheric Research, Permoserstrasse 15, 04318 Leipzig, Germany \\ ${ }^{2}$ Department of Atmospheric Environment, National Environmental Research Institute, Frederiksborgvej 399, 4000 Roskilde, \\ Denmark \\ ${ }^{3}$ UFZ Centre of Environmental Research, Department of Human Exposure Research and Epidemiology, Permoserstrasse 15, \\ 04318 Leipzig, Germany
}

Received: 23 September 2005 - Published in Atmos. Chem. Phys. Discuss.: 19 October 2005

Revised: 2 February 2006 - Accepted: 3 February 2006 - Published: 30 March 2006

\begin{abstract}
Number fractions of externally mixed particles of four different sizes $(30,50,80$, and $150 \mathrm{~nm}$ in diameter) were measured using a Volatility Tandem DMA. The system was operated in a street canyon (Eisenbahnstrasse, EI) and at an urban background site (Institute for Tropospheric Research, IfT), both in the city of Leipzig, Germany as well as at a rural site (Melpitz (ME), a village near Leipzig). Intensive campaigns of 3-5 weeks each took place in summer 2003 as well as in winter 2003/04. The data set thus obtained provides mean number fractions of externally mixed soot particles of atmospheric aerosols in differently polluted areas and different seasons (e.g. at $80 \mathrm{~nm}$ on working days, $60 \%$ (EI), 22\% (IfT), and 6\% (ME) in summer and 26\% (IfT), and $13 \%$ (ME) in winter). Furthermore, a new method is used to calculate the size distribution of these externally mixed soot particles from parallel number size distribution measurements. A decrease of the externally mixed soot fraction with decreasing urbanity and a diurnal variation linked to the daily traffic changes demonstrate, that the traffic emissions have a significant impact on the soot fraction in urban areas. This influence becomes less in rural areas, due to atmospheric mixing and transformation processes. For estimating the source strength of soot particles emitted by vehicles (veh), soot particle emission factors were calculated using the Operational Street Pollution Model (OSPM). The emission factor for an average vehicle was found to be $(1.5 \pm 0.4) \cdot 10^{14} \# /(\mathrm{km} \cdot \mathrm{veh})$. The separation of the emission factor into passenger cars $\left((5.8 \pm 2) \cdot 10^{13} \# /(\mathrm{km} \cdot \mathrm{veh})\right)$ and trucks $\left((2.5 \pm 0.9) \cdot 10^{15} \# /(\mathrm{km} \cdot \mathrm{veh})\right)$ yielded in a 40-times higher emission factor for trucks compared to passenger cars.
\end{abstract}

Correspondence to: D. Rose

(rose@mpch-mainz.mpg.de)

\section{Introduction}

Elemental carbon (EC) is one of the most important components in atmospheric aerosol. The reason for this fact is twofold. EC affects the optical properties of the aerosol, because it is the most efficient particulate light absorber (Horvath, 1993). Especially in strongly polluted regions, high absorption coefficients may decrease the single scattering albedo of the aerosol leading to atmospheric warming (e.g., Haywood and Shine, 1995). On the other hand, soot with its major compound EC is believed to play a significant role in aerosol-induced health effects (e.g., Pope and Dockery, 1999; Donaldson et al., 2001; Ye et al., 1999). Soot particles are neither water- nor lipid-soluble and have thus a completely different effect on health than water-soluble compounds (Kreyling and Scheuch, 2000).

On global scale the mass fraction of EC in the atmosphere is low and does not exceed few percent (Heintzenberg, 1989). However, the number fraction of soot particles in urban regions can be significant in the size range below $100 \mathrm{~nm}$ (Wiedensohler et al., 2000), due to the short distance to their sources, which are mainly traffic emissions. In the atmosphere, soot particles form an externally mixed subpopulation after emission. During their transport, soot particles either coagulate with other particles or are covered with material such as sulphates, nitrates or organic compounds due to condensation. The main fraction of soot particles close to the source is however externally mixed. For investigating the impact of soot in the atmosphere either on optical properties or on health effects, the partitioning of soot either as externally or internally mixed particles is important to know and to quantify for different aerosols.

Mass concentrations of EC can be measured offline using thermographic methods and cascade impactor or filter samples (e.g., Cachier et al., 1989; Nunes and Pio, 1993).

Published by Copernicus GmbH on behalf of the European Geosciences Union. 
The time resolution is usually $>1$ day and short-term variations are not resolved. Another commonly used method is based on the light transmission through a filter (aethalometer, multi-angle absorption photometer, particle soot absorption photometer). Because these instruments measure optical properties to calculate the mass concentration of EC, the results have large uncertainties. None of these techniques is able to determine the number concentration or number size distribution of soot particles directly.

Volatility techniques might provide a good estimate for the fraction of EC. In these techniques, by heating the aerosol to e.g., $300^{\circ} \mathrm{C}$, the volatile material (sulfates, nitrates, organic acids) will be evaporated. Measuring the residual nonvolatile particles and cores (non-volatile part of internally mixed particles) is thus a good indicator of the EC fraction. The most common online volatility methods to determine the (non-volatile) carbonaceous fraction are based on the principle of passing the aerosol through a heating tube, where specific chemical components are evaporated at predefined temperatures, i.e. Thermodenuder (TD) and Volatility Tandem Differential Mobility Analyzer (VTDMA) (e.g., Clarke et al., 1987; Pinnick et al., 1987; Burtscher et al., 2001). The VTDMA is an useful instrument to determine the number and volume fraction of carbonaceous material for a narrow particle size fraction $(\mathrm{Dp} \pm 10 \%)$ for atmospheric aerosol measurements (e.g., Covert and Heintzenberg, 1993; Smith and O'Dowd, 1996; Orsini et al., 1999), but also to investigate particles emitted by diesel engines on-line (Sakurai et al., 2003a,b).

In this study, the VTDMA developed by Philippin et al. (2004) was used. Here, a monodisperse particle fraction selected by a DMA is heated up to $300^{\circ} \mathrm{C}$, a temperature at which most volatile material such as sulphates, nitrates, and most of the organic compounds is evaporated. The residual particles are either the externally mixed soot particles, which do not significantly shrink, or smaller particles. These smaller residuals may consist either of soot or of other nonvolatile material such as polymers of organic carbon. Sea salt particles or crustal material is not likely to be found in the measured submicrometer size range The size distribution of all non-volatile cores can be measured employing a second DMA and a CPC as a mobility size spectrometer. Comparing the measurements at $300^{\circ} \mathrm{C}$ with the incoming concentration, the number fractions of less-volatile particles (externally mixed soot particles) and more-volatile particles (other residuals) can be determined.

Using ambient number size distributions from a mobility size spectrometer, absolute number concentrations of externally mixed soot particles can be calculated from the VTDMA number fractions at selective particle diameters. A number size distribution of the externally mixed subpopulation of soot particles can then be achieved by fitting a log normal function to the data points.

In the frame of this investigation, we employed the VTDMA in conjunction with a mobility size spectrometer mea- suring number fractions as well as number size distributions of externally mixed soot particles. We determined the externally mixed subpopulation of soot particles for different aerosol types (street canyon, urban background, and continental rural) and different seasons. Furthermore, for the first time, emission rates of diesel soot particles of passenger cars and heavy-duty vehicles were estimated from the street canyon data using the street emission model OSPM (Berkowicz et al., 1997).

\section{Experimental}

\subsection{Measurement sites}

The measurements were performed at three sites in Germany: two in the city of Leipzig, and one in Melpitz, near Leipzig.

The first station in Leipzig is a polluted street canyon near the city-center, Eisenbahnstrasse (later referred as "EI"). The street is situated in east-west direction with buildings being about $20 \mathrm{~m}$ apart and about $23 \mathrm{~m}$ high. The aerosol inlet is placed in a height of $5 \mathrm{~m}$ at the northern side of the road. By November 2003, the Eisenbahnstrasse was a busy street with about 23000 vehicles per working day driving on four lanes. The fleet consisted of $4 \%$ heavy-duty vehicles (i.e. buses, vans, and trucks). After opening a by-pass the traffic was reduced by $14 \%$ for passenger cars and by $23 \%$ for heavyduty vehicles. The driving characteristics of the vehicles in the street are highly variable and depend on the status of the nearby traffic lights and the traffic volume on the road. The measured particle concentrations represent thus a mix of different traffic conditions.

The second site in Leipzig is located on the roof of the Leibniz Institute for Tropospheric Research (later referred as "IfT") which is in the north-eastern part of Leipzig and approximately $2.5 \mathrm{~km}$ away from the Eisenbahnstrasse. The inlet is in a height of $16 \mathrm{~m}$ and higher than the surrounding buildings. The shortest distance to a street is about $200 \mathrm{~m}$. This measurement site represents the urban background aerosol (Wehner and Wiedensohler, 2003).

The third measurement site is situated near Melpitz (ME), which is a small village $40 \mathrm{~km}$ northeast of Leipzig. The research station of IfT is located on a flat meadow surrounded by agricultural land. The nearest road is a national road and is passing by $1.5 \mathrm{~km}$ in the north of the site. The station is regarded as a rural site in the continental polluted boundary layer (Spindler et al., 2001).

\subsection{Instrumentation}

Size distributions of non-volatile particle cores of certain particle sizes (here 30, 50, 80, and $150 \mathrm{~nm}$ ) were measured with a Volatility Tandem DMA (VTDMA). The VTDMA (Orsini et al., 1999) is used as an in situ technique, that evaporates volatile compounds at temperatures up to $300^{\circ} \mathrm{C}$. The VTDMA-system consists of three steps. In 
the first step, quasi-monodisperse particles in a polydisperse aerosol are selected by using a Differential Mobility Analyzer (DMA), and counted using a Condensation Particle Counter (CPC, TSI Model 3010). In the second step, the quasi-monodisperse particles are passed through a heating unit, where all volatile compounds (e.g., nitrate, sulfate, volatile organic compounds) are evaporated at $300^{\circ} \mathrm{C}$. The temperature of $300^{\circ} \mathrm{C}$ is the highest possible to avoid charring of organic matter in the particles (Cachier et al., 1989). The remaining material is assumed to consist mainly of nonvolatile elemental carbon and possibly a fraction of less volatile organic compounds (Philippin et al., 2004). In the third step, the resulting number size distribution of the nonvolatile cores is measured down to a diameter of $12 \mathrm{~nm}$ by using a second DMA/CPC-combination. The integral over this number size distribution divided by the initial counted particle concentration yields the number fraction of non-volatile particles, $N_{n v}$.

The VTDMA was operated in six intensive campaigns at the three measurement sites (EI, IfT, ME) in summer 2003 and winter 2003/04 for about four weeks each.

Additionally, the number size distributions of ambient particles in the range of 3-800 $\mathrm{nm}$ were measured for the whole time with three DMPS(Differential Mobility Particle Sizer)systems (Birmili et al., 1999), one at each measuring site.

For monitoring the traffic in the Eisenbahnstrasse, which is important for later modelling, the vehicles were counted by an optical counting system (Autoscope- Rackvision ISS, Image-Sensing-Systems). This system is able to distinguish passenger cars from heavy-duty vehicles according to the length of each car.

Parallel measurements of the meteorological parameters (wind speed, wind direction, temperature, and relative humidity) were taken at IfT. These data are also representative for the weather conditions at the roof level in the Eisenbahnstrasse.

\subsection{Data processing}

Atmospheric measurements using the VTDMA technique have shown that particles of one selected diameter may consist of different fractions of non-volatile material (e.g., Philippin et al., 2004; Sakurai et al., 2003a). As indicated in Fig. 1, there always exist particles, which are almost completely composed of non-volatile material, and which change their size less than 5\% in diameter after heating. These particles are called less-volatile particles and represent for the selected size range of 30 to $150 \mathrm{~nm}$ most likely the externally mixed population of soot particles.

Furthermore, there are particles which contain certain amounts of volatile material. They shift their diameter to smaller sizes after heating. These are so called more-volatile particles and characterize either aged soot particles with a cover of condensed volatile material or possibly polymerized organic carbon (Kalberer et al., 2004). The sum of the num-

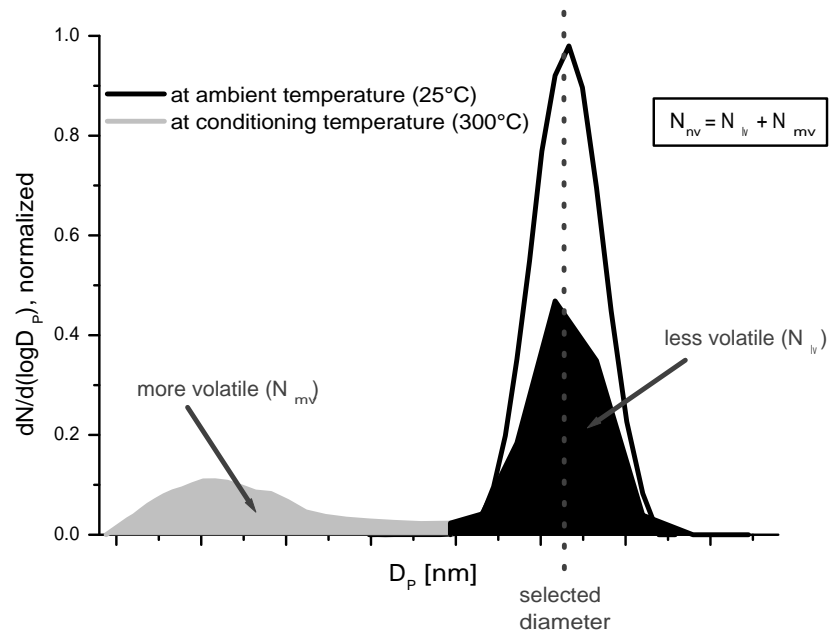

Fig. 1. Partitioning of the size distribution of non-volatile cores into a less- and a more-volatile fraction.

ber fraction of less-volatile and more-volatile particles ( $N_{l v}$ and $N_{m v}$, respectively) is equal to $N_{n v}$. It provides the percentage of particles of a certain diameter having non-volatile cores of at least $12 \mathrm{~nm}$ (lower detection limit). This concept of more- and less-volatile particles was also used in Wehner et al. (2004).

This work concentrates only on the fraction of less-volatile particles, which are assumed to be externally mixed soot particles.

Considering the size distributions measured with the DMPS-system, one can calculate a size distribution of soot particles from the $N_{l v}$. The number concentration of soot particles at a certain particle diameter results from the fraction of less-volatile particles multiplied by the number concentration of ambient particles in that diameter bin. Calculating for each particle diameter and fitting a log-normal function through the data points returns a soot number size distribution.

\section{Results and discussion}

\subsection{Seasonal and regional variability of mean number frac-} tions of soot particles

The periodic behavior of the measured data suggests a grouping of the data into working days and Sundays, which stand exemplarily for non-working days. The data on Saturdays are completely different from the rest and are omitted here.

As a first summary of the measured data the median, the 25\%-, and the 75\%-percentiles of the less-volatile particle fraction were calculated for summer and winter measurements separating into working days and Sundays. These results are presented in Fig. 2 and are shown for each selected particle diameter $(30,50,80$, and $150 \mathrm{~nm})$. 

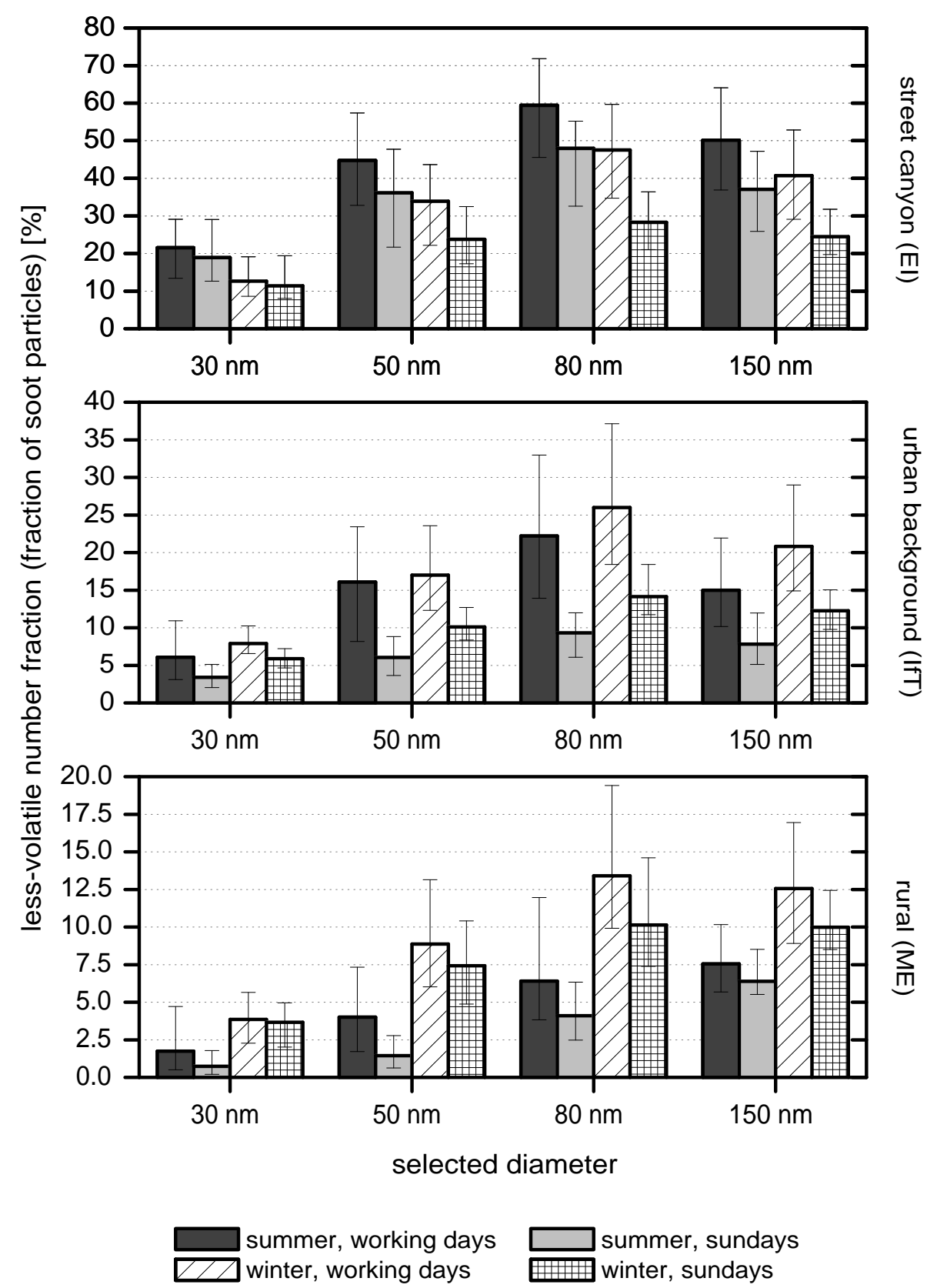

Fig. 2. Average number fraction of less-volatile particles at Eisenbahnstrasse (upper row), IfT (middle row), and Melpitz (lower row). The error bars correspond to the $25 \%$ - and $75 \%$-percentiles. Note, that there are different scales for each station.

It can be seen, that the major fraction of less-volatile particles is around $80 \mathrm{~nm}$. That corresponds to the results found in Harris and Maricq (2001), who measured size distributions of diesel exhaust. Their results show a maximum in the same size range. High fractions of less-volatile particles at $80 \mathrm{~nm}$ have also been found in former urban measurements as shown in Wehner et al. (2004).

A significant difference in the fraction of soot particles is determined between the different measurement sites. The highest fractions of soot were measured in the street canyon produced by vehicles, i.e. for $80 \mathrm{~nm}$ particles on working days in summer, $60 \%$ on average. With increasing distance from source indicating less urbanity, the fraction decreases significantly (IfT: $22 \%$, ME: 7\%). This decrease in number fraction results from mixing processes occurring during the particle transport, i.e. from dilution of soot aerosol in the street canyon with less polluted air from background. Because of intensive solar radiation, which causes a stronger destabilization of air and thus a stronger convection and resulting mixing, this process is more intensive in summer than 
Table 1. Mean total number concentration of soot particles in $\# / \mathrm{cm}^{3}$ resulting from the integral over the distributions shown in Fig. 3 . The values after \pm describe the maximum/minimum variations resulting from the integral over the log-normal fittings through the 25 - and 75\%-percentiles in Fig. 3. Note, that in winter the traffic conditions in the street canyon are not similar to those in summer. Opening a by-pass was leading to reduction of the traffic in EI during the winter measurements.

\begin{tabular}{lrrrr}
\hline \multirow{2}{*}{ measuring site } & \multicolumn{2}{c}{ summer } & \multicolumn{2}{c}{ winter } \\
& working days & Sundays & working days & Sundays \\
\hline street canyon (EI) & $6400 \pm 4250$ & $4000 \pm 1750$ & $3800 \pm 2500$ & $1800 \pm 875$ \\
urban background (IfT) & $570 \pm 375$ & $240 \pm 135$ & $770 \pm 475$ & $330 \pm 185$ \\
rural (ME) & $250 \pm 130$ & $190 \pm 65$ & $270 \pm 125$ & $230 \pm 130$ \\
\hline
\end{tabular}

in winter. In winter, the atmosphere is on average more stable and thus the removal of emissions from the ground layer is decreased. These explanations are confirmed by greater fractions of soot particles in winter (for $80 \mathrm{~nm}, 26 \%$ (IfT) and $13 \%(\mathrm{ME})$ ), in contrast to the above mentioned values in summer.

However, the measurements in the street canyon show the opposite. They show a greater amount in summer than in winter. This observation can probably be explained with a changing traffic situation, as mentioned in Sect. 2.1 (cf. Fig. 5). The traffic counts demonstrated, that with beginning of the winter measurements the number of passenger cars and especially the number of heavy duty vehicles decreased, which might have led to a lower soot fraction than in summer.

From Fig. 2 it can also be seen, that the fraction of soot particles on Sundays is significantly smaller than on working days. That is because during Sundays, the number of heavyduty vehicles, which emit probably a significant fraction of the soot particles, is much smaller than on working days.

\subsection{Number size distribution of soot particles}

As described in Sect. 2.3, the absolute number concentration of soot particles can be calculated for each selected diameter. As Harris and Maricq (2001) described their size distributions of engine emissions with a log-normal fit, this method was also used for our data, as shown in Fig. 3. This fitting allows to inter- and to extrapolate the measured data points and to integrate over the surface area under the curve, which represents the total number concentration of soot particles.

Figure 3 clearly shows the decreasing number concentration of soot particles with increasing distance from source. It can also be seen, that the geometric mean diameter of the soot mode shifts to larger sizes with distance from source. In summer, the maximum of the soot peak in the street canyon is found at a particle diameter of $65 \mathrm{~nm}$, whereas in the urban background and in the rural site it is at a diameter of 75 , and $105 \mathrm{~nm}$, respectively. In winter, the mean diameter is not as variable as in summer. It shifts only from $70 \mathrm{~nm}$ in EI to $85 \mathrm{~nm}$ in ME. The shift of soot peaks possibly arises from transformation processes in the atmosphere, which hap- pen especially to smaller particles. Due to condensation or coagulation, pure soot particles emitted by vehicles may adsorb volatile material on their way from sources to rural regions. Small particles grow relatively more than larger particles do, if they adsorb the same amount of condensing material. Therefore, smaller particles are no longer found in the mode of externally mixed soot particles. Thus, the number of smaller soot particles reduces in contrast to that of larger ones, and the mean diameter of the mode shifts relatively towards larger diameters.

The total number of soot particles, given by the integral over their number size distribution (in the size range from 3 to $800 \mathrm{~nm}$ ), is presented in Table 1. In summer, on working days, the number concentration in the street canyon was 11 times higher than at the urban background and 22 times higher than at the rural site. On Sundays, there is no significant difference between rural and urban background concentration, but between the street canyon and the background concentration. It seems to be, that the lower emissions on Sundays are not enough to influence the urban background. Thus, the concentrations at this measurement site are similar to those in Melpitz. In the street canyon, there is less mixing and therefore, the low emissions are sufficient to increase the soot concentrations significantly.

\subsection{Diurnal variation of the number fraction of soot parti- cles}

Averaging the number fraction of soot particles on working days and Sundays in a 1 -h time resolution results in a diurnal profile as shown in Fig. 4. This figure represents the results exemplarily at a selected diameter of $80 \mathrm{~nm}$. (The maximum peak of the soot mode is around $80 \mathrm{~nm}$ and this diameter shows the highest diurnal variation.) The profiles for working days contain five times more data and appear therefore much smoother than those for Sundays.

The diurnal cycle shows a similar course as the traffic cycle (cf. Fig. 5). In night hours, there are relatively small amounts of soot (about $40 \%$ in EI, $20 \%$ in IfT, and $10 \%$ in ME). The minimum is found at the time between 02:00 and 04:00. With the start of the rush-hour traffic on working 

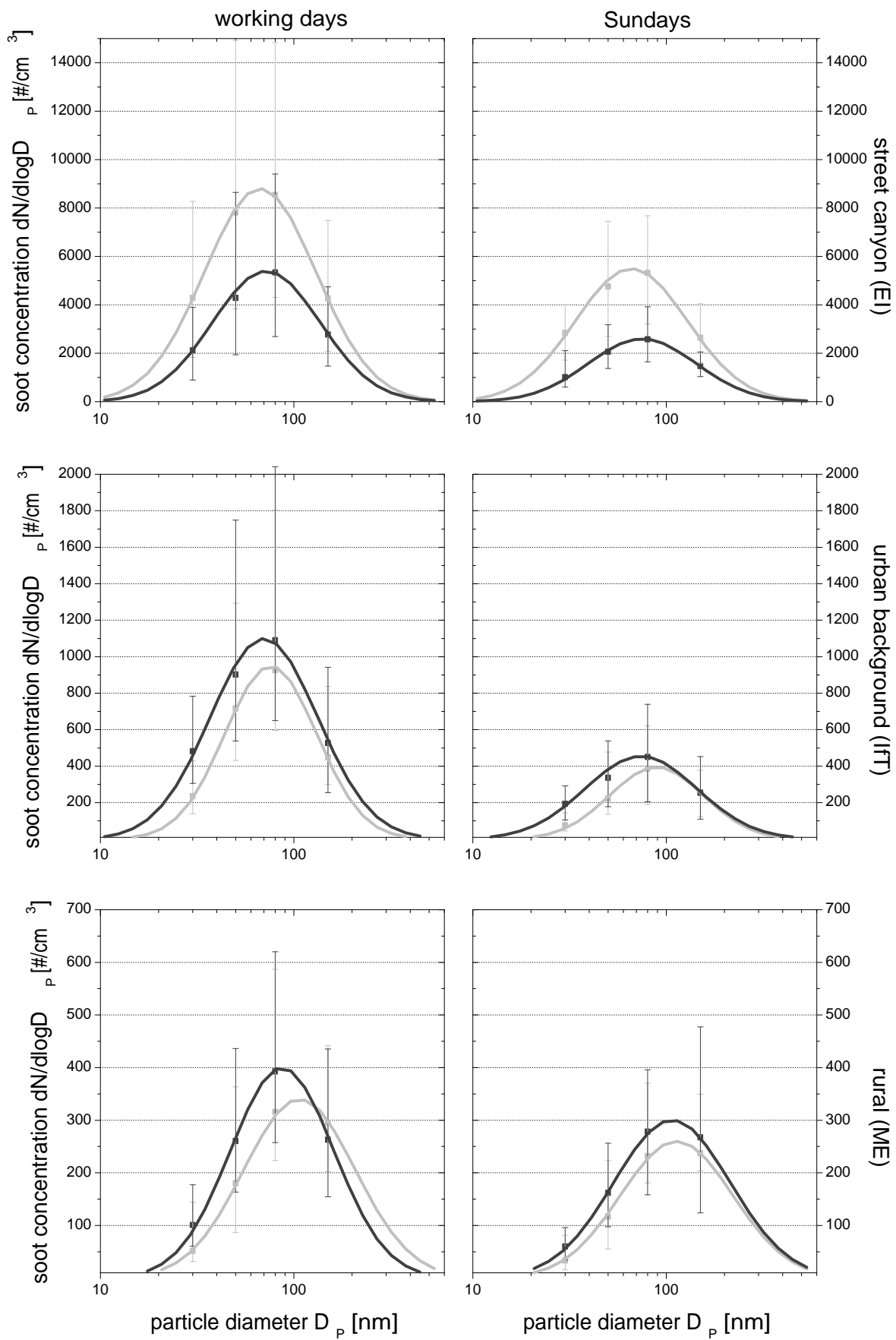

-

summer

winter

Fig. 3. Average soot particle concentration at 30,50, 80, and $150 \mathrm{~nm}$ on working days and on Sundays, calculated from VTDMA- and DMPS-data, as well as log-normal fit at Eisenbahnstrasse (upper row), IfT (middle row), and Melpitz (lower row). The error bars give the $25 \%$ - and $75 \%$-percentiles and are rather big, due to high diurnal variations. High variabilities for EI measurements result also from different wind directions within the street canyon as is being explained in Sect. 4.1.

days at 05:00, the soot fraction increases to approx. $60 \%$ in EI, $40 \%$ in IfT, and $20 \%$ in Melpitz. This first maximum is found at 07:00 to 08:00. In the urban background and rural site, the fraction decreases in summer until noon. The rea- son for this behavior seems to be the decrease in traffic and the developing boundary layer, which provides a higher dilution of the pollutants near the ground. In the afternoon, when the boundary layer is well-mixed, there are sometimes lower 


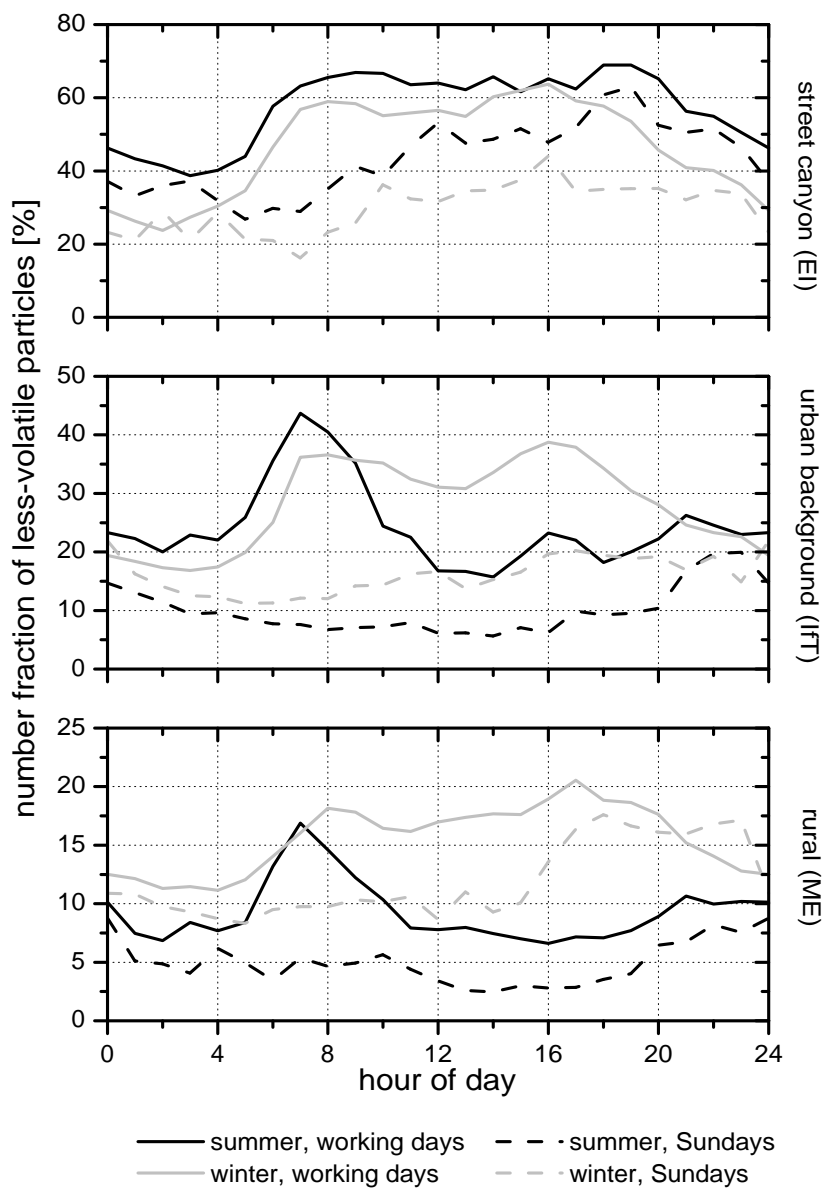

Fig. 4. Mean diurnal number fraction of soot particles of $80 \mathrm{~nm}$ in diameter at Eisenbahnstrasse (upper row), IfT (middle row), and Melpitz (lower row).

soot fractions than during nighttime. In contrast to these observations, the narrow street canyon of the Eisenbahnstrasse prevents efficient dilution. This fact leads to a persistently high soot fraction. In the evening, at the EI site, a second maximum can be seen, which corresponds to the evening rush-hour. In the late evening at every measuring site, the soot fraction decreases to its night time minimum.

In winter, after the morning maximum, the fraction of soot particles stays at its maximum level. The fraction does not decrease strongly as in summer, because of a more stable atmosphere and thus less dilution of near-ground emitted soot particles with less polluted aerosol from aloft. A second maximum in the early evening, which correlates with the maximum in traffic number can also be seen.

On Sundays, in summer, the IfT and ME site show a relatively constant temporal distribution of the soot fraction which is independent of the traffic cycle. The traffic as the primary source has less impact on the soot fraction than mixing and transformation processes. In contrast to that, in the street canyon, the traffic impact is much more important. The

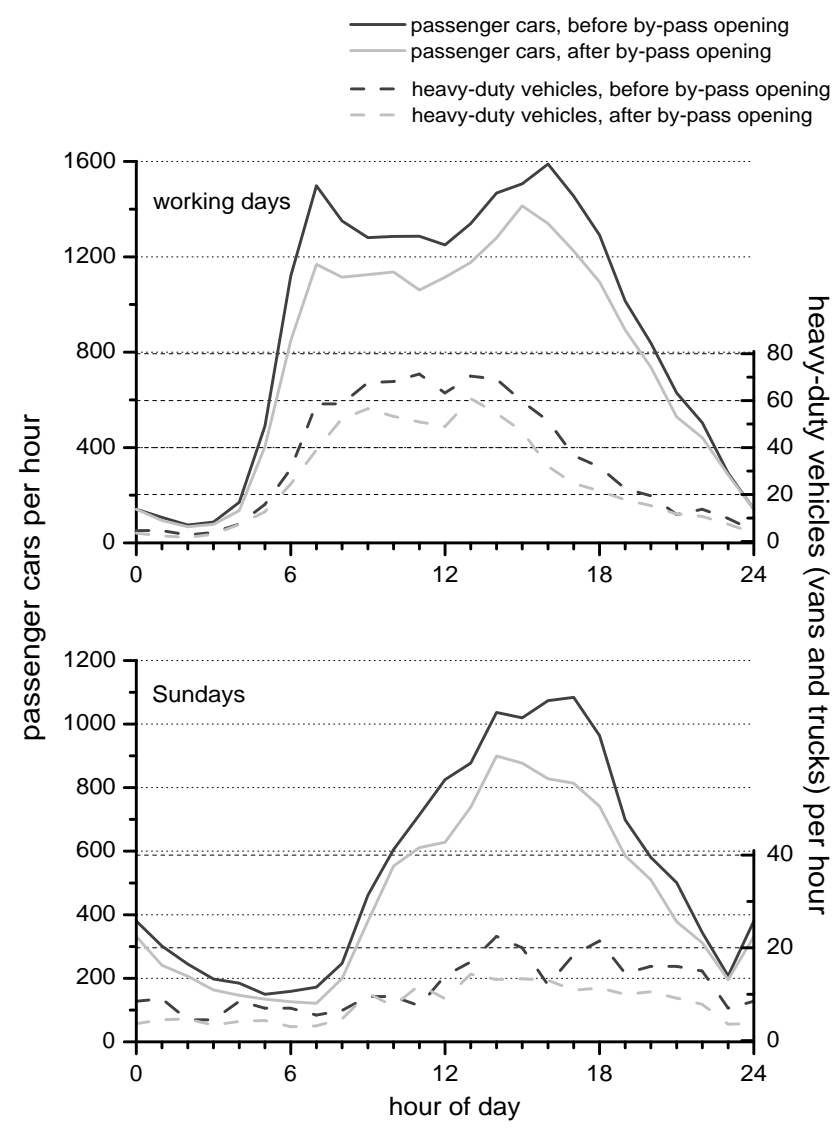

Fig. 5. Mean diurnal traffic volume at the EI-site on working days (upper row), and on Sundays (lower row).

cycle of the soot fraction follows the traffic cycle but shows a difference to that on working days. On Sundays, there is no early rush hour but an increased traffic volume in the afternoon. A maximum in the soot fraction can therefore be seen in the afternoon.

Summarizing, the fraction of soot particles depends mainly on the current traffic volume, which is shown by the diurnal variation in the EI site being parallel to diurnal traffic cycle. With increasing distance from source, this influence becomes less significant, while the influence of atmospheric mixing and transformation processes becomes more and more important. These processes change the number concentration, size, and composition of the particles and decrease therefore the number of externally mixed soot particles.

\section{Estimation of emission factors}

\subsection{Methods}

As it was shown in Sect. 3, the soot concentrations measured in the street canyon correlate with the traffic emissions. 
Furthermore, they are a function of the dilution conditions in the canyon. The dilution in a street canyon depends mainly on the wind speed (the higher the wind speed the lower the soot concentration) as well as on the wind direction. As written before, the Eisenbahnstrasse is oriented in an eastwestern direction and the monitoring station is located on the north side of the street canyon. When the wind comes from southerly directions, the monitoring station receives less polluted air from the background due to a vortex-like air circulation inside the street canyon. In contrast to that, when the wind comes from northern directions, about four times higher soot concentrations are detected at the inlet.

The relationship between the street concentration of either particle number or any trace gas and the meteorological as well as the traffic conditions was investigated by Berkowicz et al. (1997). They developed the Operational Street Pollution Model (OSPM), which is able to describe the sourcereceptor relationship in a street canyon. The usual purpose of this model is to calculate the particle or trace gas concentration in the street based on a given emission strength and meteorology. It also can be used for an inverse modelling (Palmgren et al., 1999) calculating in-situ emissions based on available measurements of the concentration, which was done during this investigation.

The emission strength in a street $Q$ can be described by (Ketzel et al., 2003):

$Q=\frac{C_{\text {street }}-C_{\text {background }}}{F(\text { meteorology,traffic })}=\frac{C_{\text {diff }}}{F}$,

where $C_{\text {street }}, C_{\text {background }}$ are the measured concentrations in the street canyon and in the urban background $\left(1 / \mathrm{cm}^{3}\right)$ (e.g. in the street/at the roof level). The difference between both variables $\left(C_{\text {diff }}\right)$ is the given contribution of the traffic to the measured street concentration. $Q$ represents the emission density $(1 /(\mathrm{m} \cdot \mathrm{s}))$, and $F$ the function describing the dilution, calculated by OSPM, $\left(\mathrm{s} / \mathrm{m}^{2}\right)$. The function $\mathrm{F}$ is equal to the concentrations using constant unit emissions and depends mainly on meteorology (wind direction and wind speed), the street geometry (building locations, heights, street orientation against north) but also on traffic flow (speed and number of vehicles). OSPM calculates $\mathrm{F}$ based on a combination of a plume model for the emissions transported directly from the vehicle exhaust to the monitoring station, and a box model for the emissions that are trapped in the street canyon and get recirculated by the vortex flow Berkowicz et al. (1997). Such vortex flows are observed on the leeward side of buildings along the street for wind components perpendicular to the street axis. If there is detailed information about traffic counts in the street, one can calculate the emission factor for each type of vehicle using the following relationship:

$Q\left(\frac{1}{\mathrm{~km} \cdot \mathrm{s}}\right)=\sum_{k} N_{k}\left(\frac{\mathrm{veh}}{\mathrm{s}}\right) \times q_{k}\left(\frac{1}{\mathrm{~km} \cdot \mathrm{veh}}\right)$

with $N_{k}$ and $q_{k}$ being the traffic flow and the emission factor for any type $k$ of vehicle.
The emission factor of a vehicle $(q)$ describes the number of particles or the mass of any trace gas emitted by a vehicle (veh) during a driving distance of one kilometer. The emission factor is also experimentally measured for vehicles on chassis dynamometers and often published in literature. These laboratory results are often very sensitive to the way the exhaust is diluted and are thus not always comparable to emissions under real world conditions (e.g., Kittelson, 1998; Graskow et al., 2000). This is the case especially for the (volatile) nucleation mode particles, i.e. smaller than 20 $30 \mathrm{~nm}$, for the (less volatile) soot mode the lab measurements are less sensitive to the dilution.

\subsection{Emission factors at Eisenbahnstrasse}

The emission factor for the total particle number and for $\mathrm{NO}_{\mathrm{x}}$ were calculated first to compare with modelled emission factors published in literature (e.g., Ketzel et al., 2003; Gidhagen et al., 2004). In a second step, emission factors for soot particles from the VTDMA measurements were calculated.

\subsubsection{Emission factors of the total particle number and $\mathrm{NO}_{\mathrm{x}}$ at Eisenbahnstrasse}

The averaged diurnal variation of the measured street contribution $C_{\text {diff }}$ for the total number of particles as well as for the $\mathrm{NO}_{\mathrm{x}}$ concentration in a certain time period (22 August 2003 to 30 September 2003) was calculated for working days. Using relationship (1) and the modeled values of the dilution function $F$ based on the measured meteorology in the urban background, the emission density $Q$ for each hour of the averaged working day was calculated. Using relationship (2) the average emission factor $q$ was calculated by dividing the emission density $Q$ by the total traffic volume $N$ for each hour of the daily profile. The traffic counts were available from the automated video counts at Eisenbahnstrasse only for a later time period but the conditions were very similar to those in August and September. The traffic volume can thus be assigned to the measuring period. The average traffic speed in the street was approx. $35 \mathrm{~km} / \mathrm{h}$.

For the daytime hours 08:00-20:00, the emission factors of particles and of $\mathrm{NO}_{\mathrm{x}}$ per average vehicle were found to be $(4.9 \pm 1.2) \cdot 10^{14} \# /(\mathrm{km} \cdot \mathrm{veh})$ and $(1.52 \pm 0.13) \mathrm{g} \mathrm{NO}_{\mathrm{x}} /(\mathrm{km} \cdot \mathrm{veh})$, respectively. The comparison with other studies shows good agreement. Measurements in a street canyon in Denmark (Jagtvej, Copenhagen) and in Stockholm reveal similar values for the particle emissions as those in Eisenbahnstrasse, with $(2.8 \pm 0.5) \cdot 10^{14} \# /(\mathrm{km} \cdot \mathrm{veh})$ and (1.3 \pm 0.2$) \mathrm{gNO}_{\mathrm{x}} /(\mathrm{km} \cdot \mathrm{veh})$ (Ketzel et al., 2003) as well as $3.9 \cdot 10^{14} \# /(\mathrm{km} \cdot \mathrm{veh})$ (Gidhagen et al., 2004), respectively. The differences between the emission factors calculated for the three street canyons basically result from different traffic conditions, due to $q$ depending on the fleet-mix. During the scandinavian measurements a heavy-traffic share of 6$8 \%$ and a $7 \%$ fraction of diesel fuelled cars was found. In 


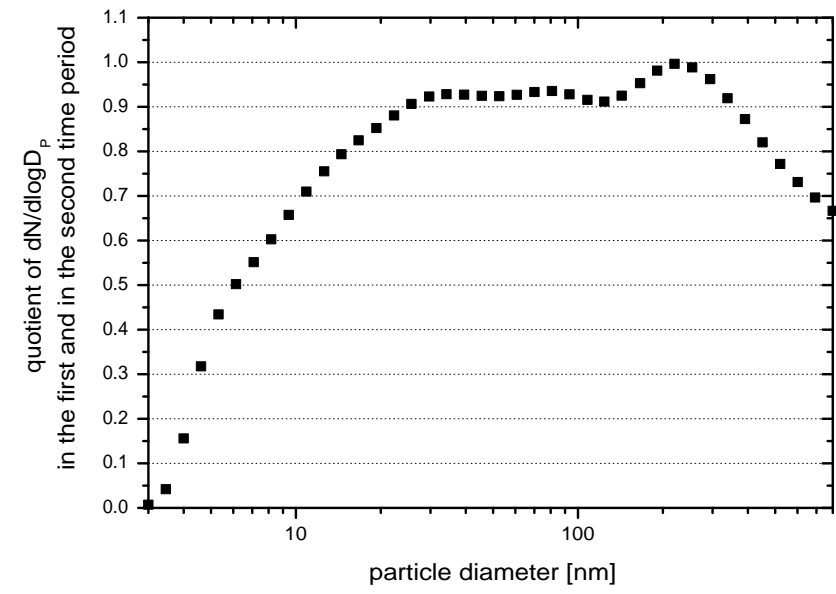

Fig. 6. Comparison of the averaged particle size distribution in the urban background (IfT) during two different time periods in summer.

contrast to that, in the Eisenbahnstrasse, the rate of heavytraffic was slightly lower $(2-5 \%)$ but the fraction of diesel cars in Germany is much higher (approx. 25\%, national study, HBEFA 2004).

\subsubsection{Emission factors of soot particles at Eisenbahnstrasse}

In the previous section it was demonstrated, that the approach used here for calculating emission factors is reasonable. In a further step, the method was thus applied to calculate also emission factors of soot particles.

The calculation of the soot particle emission factors requires the soot concentrations in the street canyon (EI) and in the urban background (IfT) simultaneously. Unfortunately, only one VTDMA-system was available and thus, the measurements had to be accomplished in different time periods. For estimating the emission factor it was therefore necessary to calculate the street contribution $C_{\text {diff }}$ from the concentrations in the street and in the urban background during different time periods. The periods were chosen according to comparable background size distributions (measured with DMPS). It was figured out, that the summer measurements in EI and IfT showed similar conditions of background aerosol, as presented in Fig. 6. So, these periods were used to calculate $C_{\text {diff. }}$.

The calculation of emission factors for soot particles was done in the same way as for the emission factors of the total particle number described in Sect. 4.2.1. They were calculated for working days and Sundays for soot particles of four different sizes $(30,50,80$, and $150 \mathrm{~nm})$. The diurnal profiles of these emission factors are shown in Fig. 7.

$q$ is the emission factor per average vehicle and thus correlates with the fleet mixture. The variation of the fleet mix is illustrated also in Fig. 7 showing the ratio of the number of heavy-duty vehicles to passenger cars. The figure demon-
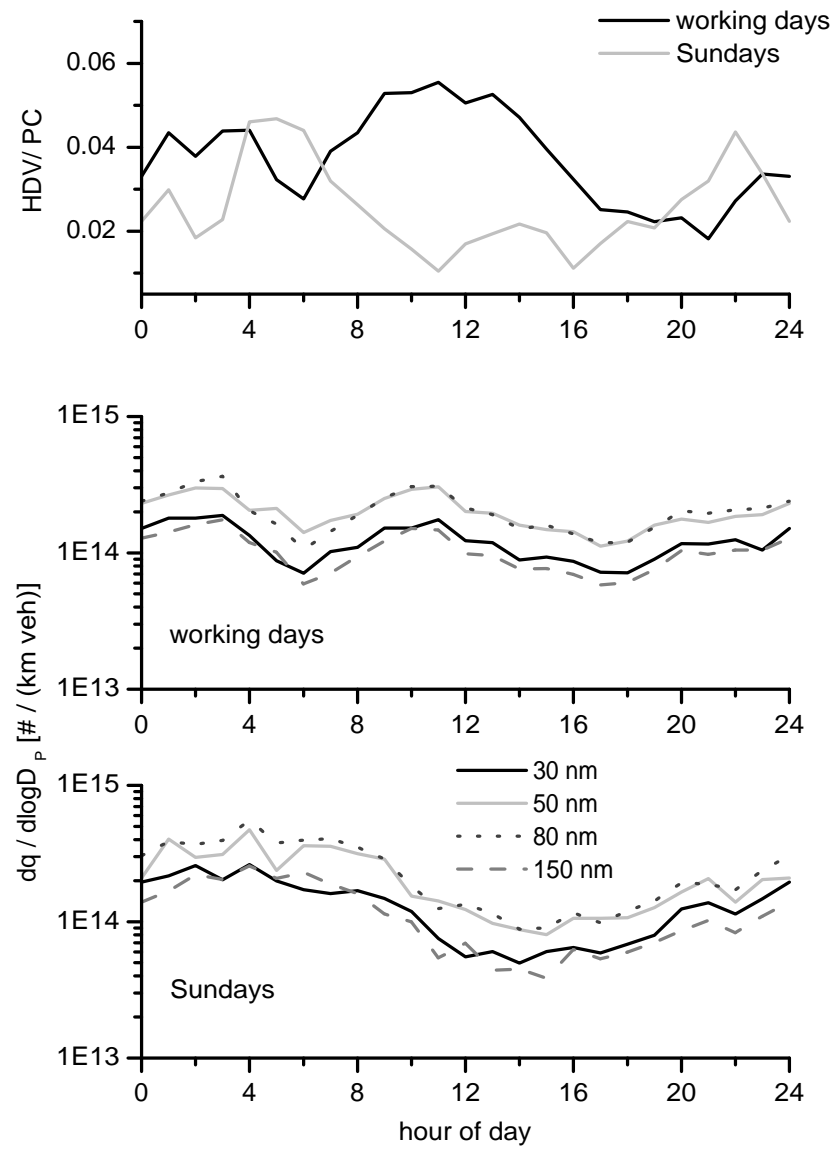

Fig. 7. Ratio of number of heavy-duty vehicles (HDV) to passenger cars (PC) (upper row), and soot emission factor per average vehicle on working days (middle row) and on Sundays (lower row).

strates, that $q$ increases, if the number of trucks increases in contrast to the number of cars and vice versa. That is due to a higher emission rate of trucks than of cars. Due to an inaccurate counting of vehicles by the camera during darkness, the errors in the vehicle ratio are significantly increased between 20:00 and 08:00.

The daytime average of $q$ on working days for each measured size is shown in Fig. 8. The integration of the number size distribution (log-normal fit) yields the total number of soot particles, which are emitted by an average vehicle over a distance of one kilometer and is $(1.5 \pm 0.4) \cdot 10^{14} \# /(\mathrm{km} \cdot \mathrm{veh})$.

Apart from calculating the emission factors of soot particles of an average car it was also possible to separate the emission factors for passenger cars and heavy-duty vehicles. For this purpose, relationship (2) was used. An equation system was set up consisting of two equations, one for working day and one for Sunday conditions. The results are presented in Fig. 8. The integral over the modes is $(5.8 \pm 2) \cdot 10^{13}$ for cars and $(2.5 \pm 0.9) \cdot 10^{15} \# /(\mathrm{km} \cdot \mathrm{veh})$ for heavy-duty vehicles. That result demonstrates, that trucks emit more than 40 times higher soot concentrations than cars. 


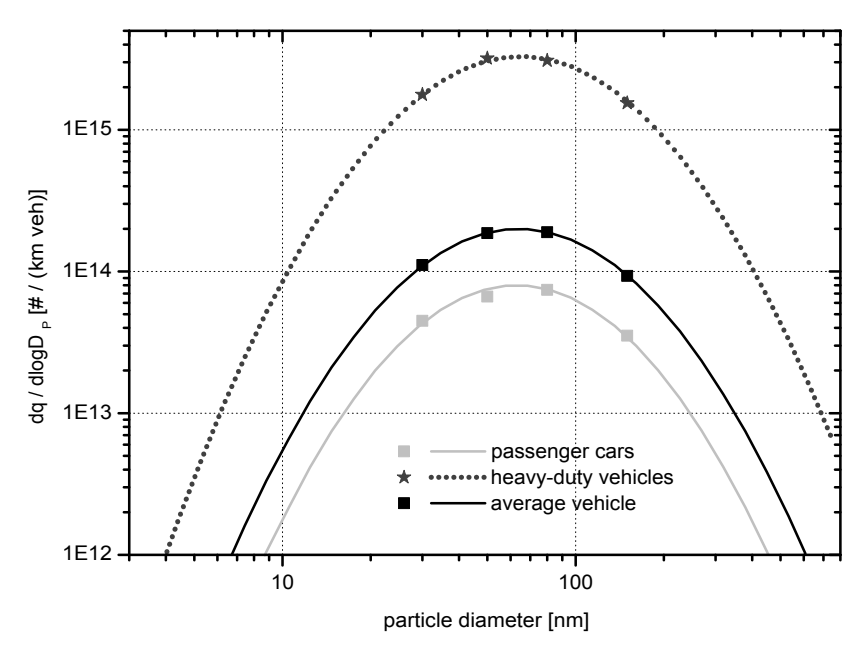

Fig. 8. Emission factor of soot particles for different kinds of vehicle.

\section{Summary and conclusions}

In the frame of this investigation, a Volatility Tandem DMA (VTDMA) was used to measure the non-volatile number fraction of submicrometer particles by evaporating volatile material of particles of certain diameters (here 30, 50, 80, and $150 \mathrm{~nm}$ ). This method was used to differentiate the fraction of externally mixed soot particles from other non-volatile material. To determine the spatial and temporal distribution of these soot particles, the VTDMA was operated at different places and in different seasons. The measurements took place in the city of Leipzig, Germany, in a street canyon (Eisenbahnstrasse, EI) as well as in the urban background (Leibniz Institute for Tropospheric Research, IfT). A third rural measuring site was located near Melpitz (ME). The VTDMA was measuring at these sites in summer 2003 as well as in winter 2003/04 during about 4 weeks each.

The number fraction of externally mixed soot particles varied for different particle diameters and showed spatial as well as temporal differences. The measurements during this campaign confirm, that the soot fraction depends on the traffic emissions to an important degree. The major fraction of soot particles was always found around $80 \mathrm{~nm}$, which corresponds to the results of diesel emission measurements. The number fraction of soot particles was decreasing with decreasing urbanity, i.e. with increasing distance from source. The highest fraction with an average of $60 \%$ at $80 \mathrm{~nm}$ was measured in the street canyon, whereas it was only $25 \%$ at the IfT-, and $15 \%$ at the ME-site. The reduction of the number fraction of externally mixed soot particles was probably caused by the dilution of these traffic emissions with less polluted background aerosol.

Seasonal variations of the soot fraction resulted mainly from the mixing layer height, which is connected to the intensity of vertical exchange. Due to a more prevalent stable atmosphere, the vertical mixing inside the boundary layer is reduced in winter time, whereas in summer convection enhances vertical mixing with cleaner air from aloft. Therefore, the emitted particles are trapped near the ground, which leads to a higher measured fraction of those particles in winter than in summer. On winter working days, the soot fraction was $13 \%$ at the rural site, and $26 \%$ at the urban background, but in summer, it was only $6 \%$ and $22 \%$, respectively. The results from the street canyon were not comparable in this way, because the traffic conditions were not similar during both measuring periods.

The diurnal cycle of the soot fractions followed the diurnal cycle of the traffic, especially in the street canyon. With increasing number of cars and trucks, the number fraction of soot particles was increasing. The soot fractions at the IfT and in ME correlated also with the traffic conditions on nearby roads, but in summer this behavior was more controlled by meteorology, i.e. with starting convection in the later morning, the soot fraction was decreasing even though the number of vehicles was not reducing.

Using the ambient number size distributions from parallel DMPS measurements, the number size distribution of the externally mixed subpopulation of soot particles was calculated. The total number concentration of soot particles, estimated by integrating the number size distribution, was approx. $6500 \# / \mathrm{cm}^{3}$ at the EI-station in summer. This concentration is more than 10 times higher than in the urban background and more than 20 times higher than in the rural site.

Combining the number concentration of soot particles in the street canyon and in the urban background in a street pollution model (OSPM), emission factors of soot particles were calculated. In contrast to the emission factors measured at chassis dynamometers, they give information about the emissions resulting from real driving conditions, real fleet averages and from atmospheric mixing processes. The emission factor of an average vehicle was found to be $(1.5 \pm 0.4) \cdot 10^{14} \# /(\mathrm{km} \cdot \mathrm{veh})$. This value depends on the fleet, which consisted of $96 \%$ passenger cars and of $4 \%$ trucks, busses, etc. on working days. The separation of the emissions into passenger cars and heavy-duty vehicles led to a more than 40 times higher emission factor for heavy-duty vehicles than for cars.

This study demonstrates, that the traffic emissions have a major impact on the particle number concentration in urban atmosphere. Soot particles mainly originating from combustion of fossil fuels in vehicles are emitted into the atmosphere and form an externally mixed subpopulation. The presented emission factors provide a number concentration of how many particles are emitted.

Due to atmospheric mixing and transformation processes the fraction of soot particles decreases with increasing distance from source but can stay significantly even in rural regions. The averaged fractions measured during this campaign can be seen as standards for places similar with respect 
to climate and car fleet and could be used in future transport or climate model studies.

Acknowledgements. This work was funded by the FAT (Fördervereinigung Automobiltechnik).

Edited by: U. Lohmann

\section{References}

Berkowicz, R., Hertel, O., Larsen, S. E., Sørensen, N. N., and Nielsen, M.: Modelling traffic pollution in streets, National Environmental Research Institute, Roskilde, Denmark, 1997.

Birmili, W., Stratmann, F., and Wiedensohler, A.: Design of a DMA-based size spectrometer for a large particle size range and stable operation, J. Aerosol Sci., 30, 549-553, 1999.

Burtscher, H., Baltensperger, U., Buckowiecki, N., Cohn, P., Hüglin, C., Mohr, M., Matter, U., Nyeki, S., Schmatloch, V., Streit, N., and Weingartner, E.: Separation of volatile and nonvolatile aerosol fractions by thermodesorption: instrumental development and applications, J. Aerosol Sci., 32, 427-442, 2001.

Cachier, H., Brémond, M.-P., and Buat-Ménard, P.: Determination of atmospheric soot carbon with a simple thermal method, Tellus, 41B, 379-390, 1989.

Clarke, A., Ahlquist, N., and Covert, D.: The Pacific marine aerosol: evidence for natural acid sulfates, J. Geophys. Res., 92, 4179-4190, 1987.

Covert, D. and Heintzenberg, J.: Size distributions and chemical properties of aerosol at Ny-Ålesund, Svalbard, Atmos. Environ., 27A, 2989-2997, 1993.

Donaldson, K., Stone, V., Seaton, A., and MacNee, W.: Ambient Particle Inhalation and the Cardiovascular System: Potential Mechanisms, Environ. H. Per., 109, 523-527, 2001.

Gidhagen, L., Johansson, C., Langner, J., and Olivares, G.: Simulation of $\mathrm{NO}_{\mathrm{x}}$ and ultrafine particles in a street canyon in Stockholm, Sweden, Atmos. Environ., 38, 2029-2044, 2004.

Graskow, B. R., Ahmadi, M. R., Morris, J. E., and Kittelson, D. B.: Influence of fuel additives and dilution conditions on the formation and emission of exhaust particulate matter from a direct-injection, spark-ignition engine, SAE Paper, 2000-012018, 2000.

Harris, S. J. and Maricq, M. M.: Signature size distributions for diesel and gasoline engine exhaust particulate matter, J. Aerosol Sci., 32, 749-764, 2001.

Haywood, J. and Shine, K.: The effect of anthropogenic sulfate and soot aerosol on the clear sky planetary radiation budget, Geophys. Res. Lett., 22, 603-606, 1995.

Heintzenberg, J.: Fine particles in the global troposphere, A review, Tellus, 41B, 149-160, 1989.

Horvath, H.: Atmospheric Light Absorption - A Review, Atmos. Environ., 27A, 293-317, 1993.

Kalberer, M., Paulsen, D., Sax, M., Steinbacher, M., Dommen, J., Prevot, A. S. H., Fisseha, R., Weingartner, E., Frankevich, V., Zenobi, R., and Baltensperger, U.: Identification of Polymers as Major Components of Atmospheric Organic Aerosols, Science, 303, 1659-1662, 2004.

Ketzel, M., Wåhlin, P., Berkowicz, R., and Palmgren, F.: Particle and trace gas emission factors under urban driving conditions in
Copenhagen based on street and roof-level observations, Atmos. Environ., 37, 2735-2749, 2003.

Kittelson, D. B.: Engines and nanoparticles: A review, J. Aerosol Sci., 29, 575-588, 1998.

Kreyling, W. G. and Scheuch, G.: Clearance of particles deposited in the lungs, in Particle-Lung Interactions, edited by: Gehr, P. and Heyder, J., 323-376, 2000.

Nunes, T. V. and Pio, C. A.: Carbonaceous aerosols in industrial and coastal atmospheres, Atmos. Environ., 27A, 1339-1346, 1993.

Orsini, D. A., Wiedensohler, A., Stratmann, F., and Covert, D. S.: A New Volatility Tandem Differential Mobility Analyzer to Measure the Volatile Sulfuric Acid Aerosol Fraction, J. Atmos. Ocean., 16, 760-772, 1999.

Palmgren, F., Berkowicz, R., Ziv, A., and Hertel, O.: Actual car fleet emissions estimated from urban air quality measurements and street pollution models, Sci. Total Environ., 235, 101-109, 1999.

Philippin, S., Wiedensohler, A., and Stratmann, F.: Measurements of non-volatile fractions of pollution aerosols with an eight-tube volatility tandem differential mobility analyzer (VTDMA-8), J. Aerosol Sci., 35, 185-203, 2004.

Pinnick, R., Jennings, S., and Fernandez, G.: Volatility of aerosols in the arid southwestern United States, J. Atmos. Sci., 44, 562576, 1987.

Pope, C. A. and Dockery, D. W.: Epidemiology of Particle Effects, in: Air Pollution and Health, edited by: Holgate, S. T., Samet, J. M., Koren, H. S., and Maynard, R. L., Academic Press, 673705, 1999.

Sakurai, H., Tobias, H. J., Park, K., Zarling, D., Docherty, K. S., Kittelson, D. B., McMurry, P. H., and Ziemann, P.: On-line measurements of diesel nanoparticle composition and volatility, Atmos. Environ., 37, 1199-1210, 2003a.

Sakurai, H., Park, K., McMurry, P., Zarling, D., Kittelson, D., and Ziemann, P.: Size-dependent mixing characteristics of volatile and nonvolatile components in diesel exhaust aerosols, Environ. Sci. Technol., 37, 5487-5495, 2003b.

Smith, M. and O'Dowd, C.: Observations of accumulation mode aerosol composition and soot carbon concentrations by means of a high-temperature volatility technique, J. Geophys. Res., 101, 19583-19591, 1996.

Spindler, G., Teichmann, U., and Sutton, M. A.: Ammonia dry deposition over grassland-micrometeorological fluux-gradient measurements and bidirectional flux calculations using an inferential model, Quart. J. Roy. Meteorol. Soc., 127, 795-814, 2001.

Wehner, B. and Wiedensohler, A.: Long term measurements of submicrometer urban aerosols: statistical analysis for correlations with meteorological conditions and trace gases, Atmos. Chem. Phys., 3, 867-879, 2003.

Wehner, B., Philippin, S., Wiedensohler, A., Scheer, V., and Vogt, R.: Variability of non-volatile fractions of atmospheric aerosol particles with traffic influence, Atmos. Environ., 38, 6081-6090, 2004.

Wiedensohler, A., Stratmann, F., and Tegen, I.: Environmental Particles, in: Particle-Lung Interactions, edited by: Gehr, P. and Heyder, J., 67-88, 2000.

Ye, S., Zhou, W., Song, J., Peng, B., Yuan, D., Lu, Y., and Qi, P.: Ambient Particle Inhalation and the Cardiovascular System: Potential Mechanisms, Atmos. Environ., 34, 419-429, 1999. 